\title{
Oral Glutamine Attenuates Cyclophosphamide-Induced Oxidative Stress in the Bladder but Does Not Prevent Hemorrhagic Cystitis in Rats
}

\author{
Premila Abraham • Bina Isaac • \\ Hemalatha Ramamoorthy $\cdot$ Kasthuri Natarajan
}

Published online: 27 July 2010

(C) American College of Medical Toxicology 2010

\begin{abstract}
Cyclophosphamide (CP) is widely used in the treatment of cancer and non-malignant disease states such as rheumatoid arthritis. Hemorrhagic cystitis is a major dose-limiting side effect of CP. The incidence of this side effect is related to the dosage and can be as high as $75 \%$. Elimination of the side effects of CP can lead to better tolerance of the drug, and a more efficient therapy can be achieved for patients in need of CP treatment. Several studies have demonstrated that oxidative stress and neutrophil infiltration play important roles in CP-induced bladder damage. Glutamine is utilized under clinical conditions for preventing chemotherapeutic drug-induced side effects, based on its ability to attenuate oxidative stress. The aim of the study is to verify whether glutamine prevents CPinduced oxidative stress and bladder damage using a rat model. Adult male rats were administered $150 \mathrm{mg} / \mathrm{kg}$ body weight of CP intraperitoneally. Glutamine pretreated rats were administered $1 \mathrm{~g} / \mathrm{kg}$ body weight of glutamine orally $2 \mathrm{~h}$ before the administration of CP. Vehicle/ glutamine-treated rats served as controls. All the rats were killed $16 \mathrm{~h}$ after the dose of $\mathrm{CP} /$ vehicle. The urinary bladders were removed and used for light microscopic and biochemical studies. The markers of oxidative stress including malondialdehyde content, protein carbonyl con-
\end{abstract}

P. Abraham $(\bowtie) \cdot H$. Ramamoorthy $\cdot$ K. Natarajan

Department of Biochemistry, Christian Medical College,

Bagayam,

Vellore 632002, Tamil Nadu, India

e-mail: premilaabraham@yahoo.com

e-mail: premilaabraham@cmcvellore.ac.in

B. Isaac

Department of Anatomy, Christian Medical College, Bagayam,

Vellore 632002, Tamil Nadu, India tent, protein thiol, and myeloperoxidase activity, a marker of neutrophil infiltration, were measured in bladder homogenates. CP treatment induced hemorrhagic cystitis in the rats. Pretreatment with glutamine significantly reduced CPinduced lipid peroxidation $(p<0.01)$, protein oxidation $(p<0.01)$, and increase in myeloperoxidase activity $(p<0.05)$. However, it did not prevent CP-induced bladder damage. The results of the present study show that glutamine pretreatment does not attenuate CP-induced hemorrhagic cystitis, although it prevents CP-induced oxidative stress and neutrophil infiltration significantly. It is therefore necessary to clarify the utility of glutamine as a chemoprotective agent before it is recommended in the market as a nutrient supplement.

Keywords Cyclophosphamide · Hemorrhagic cystitis . Oxidative stress $\cdot$ Glutamine $\cdot$ Rat

\section{Introduction}

Cyclophosphamide (CP) is a drug with a wide spectrum of clinical uses, and it has been proved to be effective in the treatment of cancer (lymphoma, acute and chronic leukemias, and multiple myeloma) and non-malignant disease states such as rheumatoid arthritis [1]. However, this drug may induce acute inflammation of the urinary bladder (cystitis) $[2,3]$. Hemorrhagic cystitis (HC) is a major doselimiting side effect of $\mathrm{CP}$ [1]. The incidence of this side effect can be great $(75 \%)$ in patients receiving a high intravenous dose. Elimination of the urotoxicity of $\mathrm{CP}$ could lead to better tolerance of the drug, and more efficient and comfortable therapy could be achieved for patients in need of CP treatment. 
Recent studies have shown that reactive oxygen species (ROS) play an important role in CP-induced HC. These studies have shown that the indicator of oxidative stress, namely malondialdehyde (MDA), increases in the bladder after the administration of CP. The role of ROS in the pathogenesis of CP-induced $\mathrm{HC}$ is supported by the findings that antioxidants such as tocopherol, taurine, carotene, and melatonin protect against $\mathrm{CP}$-induced $\mathrm{HC}$ [4-6]. Sadir et al. [4] have demonstrated that MDA levels increase significantly in bladder tissue after CP injection and the antioxidants ameliorated this increase. Abd-Allah et al. [6] demonstrated a significant decrease in the endogenous antioxidant compound glutathione and elevation of lipid peroxidation in rat urinary bladder tissue after the administration of CP. They have also shown that taurine pretreatment resulted in a significant decrease in lipid peroxide and restoration of glutathione content in urinary bladder tissue.

Glutamine (GLN) is the most abundant amino acid found in blood and in the free amino acid pool of the human body [7]. Besides its role as a constituent of proteins and its importance as metabolic fuel, glutamine has nonnutritive effects, including regulation of the cellular redox balance [8], cell volume [9], glutathione metabolism [10], and attenuation of oxidative stress [11-13].

Several studies have shown that glutamine administration attenuates oxidative stress and protects against chemotherapeutic agent induced organ injury. These include anthracycline-induced mucositis/stomatitis in breast cancer patients [14], fluorouracil-induced stomatitis in patients with advanced or metastatic cancer [15], and oxaliplatininduced peripheral neuropathy in colorectal cancer patients [16]. In rats, oral glutamine has been shown to attenuate oxidative stress in cyclophosphamide-induced cardiotoxicty [17].

Because of the high turnover rate of glutamine, it is suggested that even high amounts of glutamine can be given without any important side effects. It is suggested that if glutamine is shown to prevent CP-induced oxidative stress and urotoxicity, it can lead to better tolerance of the drug. Thus, a more efficient therapy can be achieved for patients in need of $\mathrm{CP}$ treatment. Therefore, the purpose of the present study was to investigate whether the administration of the glutamine has any protective effect against cyclophosphamide-induced oxidative stress and urotoxicity in rats.

\section{Materials and Methods}

Chemicals

Glutamine powder, 1-chloro-2,4-dinitrobenzene, bovine serum albumin powder, 5,5-dithio-bis-(2-nitrobenzoic acid)
(DTNB), reduced glutathione 2-thiobarbituric acid, and 1,1,3,3 tetramethoxy propane were obtained from Sigma Chemical Co., St. Louis, MO, USA. All other chemicals were of analytical grade.

Animals and Treatments

Adult male Wistar rats (200-250 g) were used for the experiments. The study was approved by the animal ethics Committee for the Purpose of Control and Supervision of Experimentation on Animals (CPCSEA), Government of India. The guidelines of CPCSEA were followed. Dosage and route of administration of CP were determined from that described in literature the [18]. Todora et al. have recently demonstrated that GLN at the dose of $1 \mathrm{~g} / \mathrm{kg}$ body weight protects against CP-induced cardiotoxicity in rats [17]. Therefore, we used the same dose for our study. CP was dissolved in $0.9 \%$ saline, and glutamine was dissolved in water.

\section{Experimental Design}

The rats were divided into four groups and were treated as follows.

Group I (Vehicle Control) The rats in this group $(n=6)$ received saline (the vehicle for $\mathrm{CP}$ ) and water (the vehicle for glutamine).

Group II (Glutamine) The rats $(n=6)$ in this group received $1 \mathrm{~g} / \mathrm{kg}$ body weight glutamine dissolved in water orally.

Group III (CP Alone) The rats in this group $(n=8)$ received a single intraperitoneal injection of $\mathrm{CP}$ in saline at the dose of $150 \mathrm{mg} / \mathrm{kg}$ body weight.

Group IV $(C P+$ Glutamine $)$ The rats in this group $(n=8)$ received $1 \mathrm{~g} / \mathrm{kg}$ body weight of glutamine orally. Two hours later, they received a single intraperitoneal injection of $\mathrm{CP}$ in saline at the dose of $150 \mathrm{mg} / \mathrm{kg}$ body weight.

The rats were killed $16 \mathrm{~h}$ after the administration of $\mathrm{CP}$ or saline. The urinary bladders were removed and blotted dry before weighing. A part of the urinary bladder was used for biochemical assays and another part for histological assessment by light microscopy.

\section{Light Microscopy of the Urinary Bladder}

The tissues were fixed overnight in $10 \%$ buffered neutral formalin, processed to paraffin wax, sectioned at $5 \mu \mathrm{m}$, and stained with hematoxylin and eosin for examination by light microscopy. 
Biochemical Assays The biochemical assays were carried out on $10 \%(w / v)$ of bladder tissue homogenates.

\section{Malondialdehyde}

Malondialdehyde content was measured as described by Ohkawa et al. [19]. The mixture consisted of $0.8 \mathrm{ml}$ of sample, $0.2 \mathrm{ml}$ of $8.1 \%$ SDS, $1.5 \mathrm{ml}$ of $20 \%$ glacial acetic acid adjusted to $\mathrm{pH} 3.5$, and $1.5 \mathrm{ml}$ of $0.8 \%$ aqueous solution of TBA. The mixture was made up to $4 \mathrm{ml}$ with distilled water and heated at $95^{\circ} \mathrm{C}$ for 60 min using a glass ball as condenser. After cooling with tap water, $1 \mathrm{ml}$ distilled water and $5 \mathrm{ml} n$-butanol and pyridine mixture $(15: 1)$ were added, and the solution was shaken vigorously. After centrifugation at $2,000 \times g$ for $10 \mathrm{~min}$, the absorbance of the organic layer was measured at $532 \mathrm{~nm}$. Amount of thiobarbituric reacting substances formed is calculated from standard curve prepared using $1,1^{\prime}, 3,3^{\prime}$ tetramethoxy propane, and the values were expressed as nanomoles per milligram protein

\section{Protein Carbonyl Content}

Protein carbonyl content was measured using DNPH as described by Sohal et al. [20]. To $0.5 \mathrm{ml}$ of sample, an equal volume of $10 \mathrm{mM} \mathrm{DNPH}$ in $2 \mathrm{~N} \mathrm{HCl}$ was added and incubated for $1 \mathrm{~h}$ shaking intermittently at room temperature. Corresponding blank was carried out by adding only $2 \mathrm{~N} \mathrm{HCl}$ to the sample. After incubation, the mixture was precipitated with $10 \%$ TCA (final concentration) and centrifuged. The precipitate was washed twice with ethanol/ethylacetate $(1: 1)$ and finally dissolved in $1 \mathrm{ml}$ of $6 \mathrm{M}$ guanidine $\mathrm{HCl}$ and centrifuged at low speed, and the supernatant was read at $366 \mathrm{~nm}$. The difference in absorbance between the DNPH- and HCl-treated sample was determined and expressed as nanomoles of carbonyl groups per milligram of protein, using extinction coefficient of $22 \mathrm{mM}^{-1} \mathrm{~cm}^{-1}$.

\section{Protein Thiol Groups}

Thiol groups were measured as described by Habeeb [21]. To $1 \mathrm{ml}$ of the sample suspension, $1 \mathrm{ml}$ of $10 \%$ TCA containing $1 \mathrm{mM}$ EDTA was added. The protein precipitate was separated by high-speed centrifugation $(10,000 \times g)$ for $10 \mathrm{~min}$. For total thiol estimation, the sample was taken directly without precipitation. To this, $1 \mathrm{ml}$ of solution I and $0.5 \%$ SDS were added followed by $2 \mathrm{ml}$ of solution II and $30 \mu \mathrm{l}$ of DTNB. The tubes were mixed well and kept in the dark for $15 \mathrm{~min}$ at room temperature. The intense yellow color of the nitromercaptobenzoate anion formed from the DTNB reaction with the thiol was read at $412 \mathrm{~nm}$, which has a molar absorption of
$13,600 \mathrm{~m}^{-1} \mathrm{~cm}^{-1}$. The results are expressed in micromole per milligram protein.

\section{Myeloperoxidase Activity}

Myeloperoxidase activity was measured with $O$-dianisidine- $\mathrm{H}_{2} \mathrm{O}_{2}$ by Diaz-Granados method [22]. The rate of decomposition of $\mathrm{H}_{2} \mathrm{O}_{2}$ by myeloperoxidase was determined by measuring the rate of color development at $460 \mathrm{~nm}$. To $10 \mu \mathrm{l}$ of sample, $11 \mu \mathrm{l}$ of $\mathrm{H}_{2} \mathrm{O}_{2}, 17 \mu \mathrm{l}$ of $O$ dianisidine, and $962 \mu 1$ of phosphate buffer were added, and the color was read at $460 \mathrm{~nm}$ at an interval of $30 \mathrm{~s}$ for $4 \mathrm{~min}$, and the rate of change per minute was determined. Extinction coefficient of $1.13 \times 10^{4} \mathrm{~cm}^{-1}$ was used for the calculation. One unit is the amount of enzyme decomposing $1 \mu \mathrm{mol}$ of peroxide per minute.

Protein was measured by the Lowry method [23].

\section{Statistical Analysis}

A power analysis was done. A sample size of minimum six was to be used for our study. The data represent mean values $\pm \mathrm{SD}$. Means of the four groups were compared by ANOVA. In the case of a significant $F$, Student's $t$ test with Bonferroni correction was used to compare individual means. A $P$ value of $<0.05$ was considered to be statistically significant.

\section{Results}

\section{Light Microscopic Studies}

In the control rats (both vehicle treated and glutamine treated), the bladders had normal structure. The urinary bladder had the urothelium formed by tightly packed cells with little intercellular space. The basement membrane that separates the epithelium from the underlying lamina propria was intact. There was no breach in it. The connective tissue that constituted the lamina propria was dense with normal vascular supply. The mucosa was thrown into folds, and there were subepithelial crypts. The smooth muscle coat underlying the lamina propria displayed circular and longitudinal muscle coat with minimal connective tissue packing. There were no exudates in the lumen (Fig. 1a).

Contrary to the normal picture presented above, the bladder wall in CP-treated animals showed severe damage. The mucosa was edematous, and the cells of the urothelium were not compact. Cellular exudates were seen in the lumen. Mucosal content formed follicular cystitis (Fig. 1c). Edema of lamina propria with epithelial and subepithelial hemorrhage was seen (arrows in Fig. 1c). The epithelium showed patches of ulceration (arrow in Fig. 1c). The lamina propria was 
Fig. 1 Light microscopy of the bladders of control rats and experimental rats. Original magnification, $\times 100$. a Saline control rats with normal morphology. Arrow points to folded mucosa, with epithelium showing tight packing of cells and dense connective tissue in lamina propria. Subepithelial crypts also seen. No hemorrhage found. b Glutamine-treated rats with normal epithelium and lamina propria. c Bladder from cyclophosphamide-treated rat showing edema of epithelium, and it appears that epithelium has been breached. Vascular changes in lamina propria are apparent. d Bladder from GLN $+\mathrm{CP}$-treated rat showing degeneration of the epithelium, edema in the lamina propria, and erosion of the mucosa
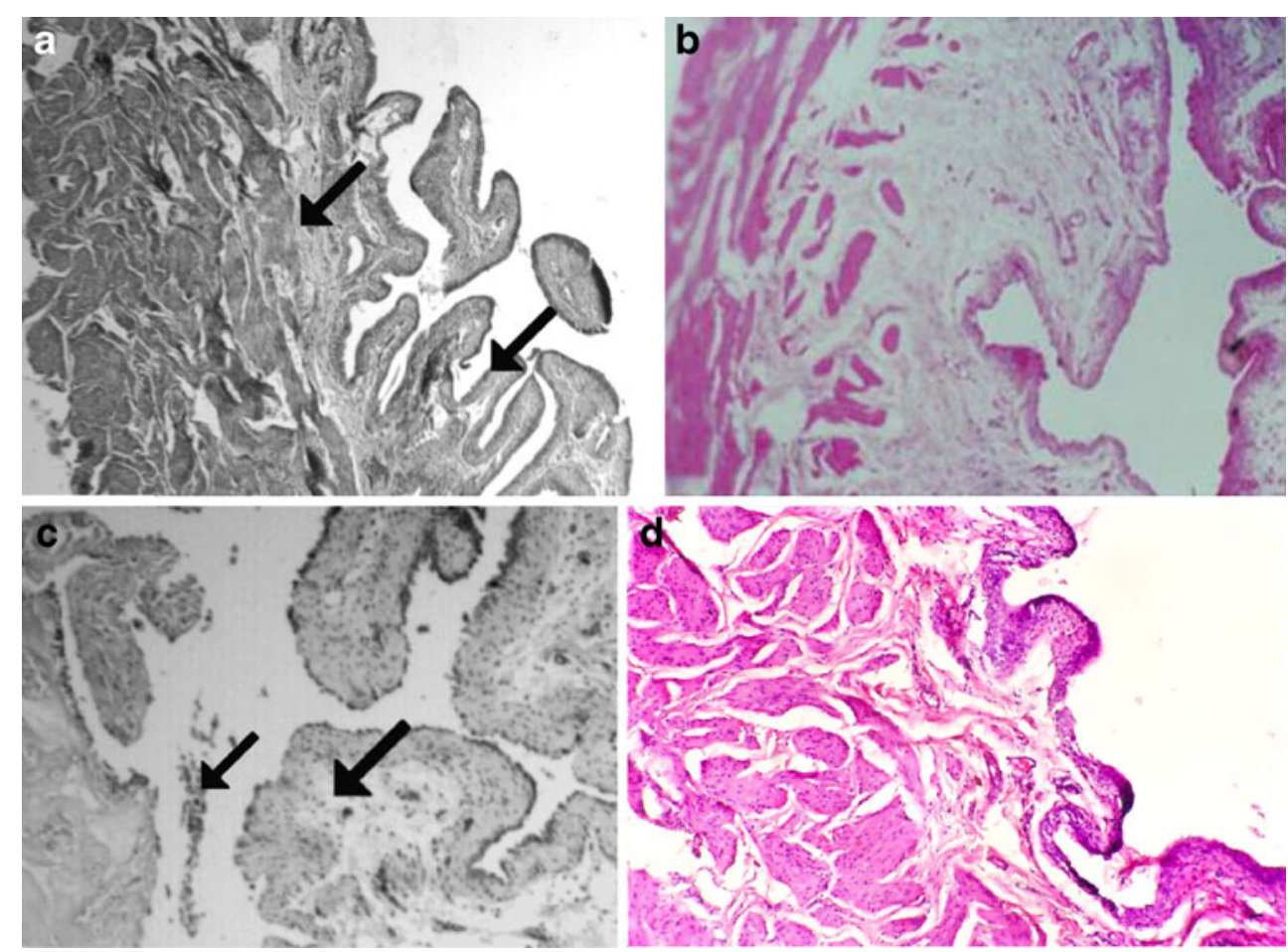

edematous, and there were exudates in the lumen (arrow in Fig. 1c).

Pretreatment with glutamine did not prevent $\mathrm{CP}$-induced hemorrhagic cystitis (Fig. 1d). The epithelia were detached from the lamina propria and appear degenerated. The mucosa was eroded, and severe edema was observed.

\section{Biochemical Parameters}

The biochemical parameters are shown in Figs. 2, 3, 4, and 5.

\section{MDA Level}

The MDA level in the bladder of CP-treated rats was elevated by $292 \%$ as compared with the control $(p<0.01)$.

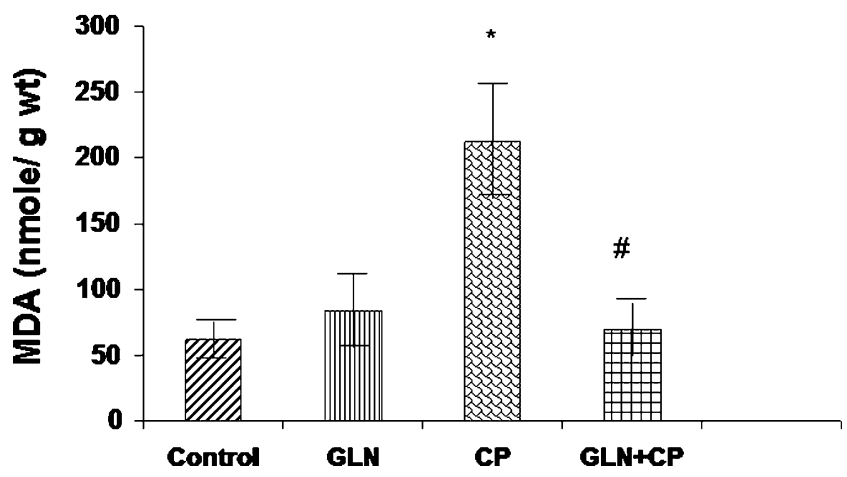

Fig. 2 MDA levels in the bladders of control rats and experimental rats. Data represent mean $\pm \mathrm{SD}$ of five to seven rats. $* P<0.01$ vs control, GLN, ${ }^{\#} P<0.01$ vs $\mathrm{CP}$
Pretreatment with glutamine completely prevented CPinduced increased MDA level $(P<0.01)$ (Fig. 2).

\section{Protein Carbonyl Content}

The bladder protein carbonyl content in the CP-treated rats was increased by $219 \%$ as compared with the control $(P<0.01)$. Pretreatment with glutamine partially but significantly prevented $\mathrm{CP}$-induced increase in protein carbonyl content $(P<0.01)$ (Fig. 3).

\section{Protein Thiol}

Protein thiol was increased by $61 \%$ in the bladders of CPtreated rats as compared with control $(P<0.01)$. Pretreatment with glutamine had no effect on protein thiol level (Fig. 4).

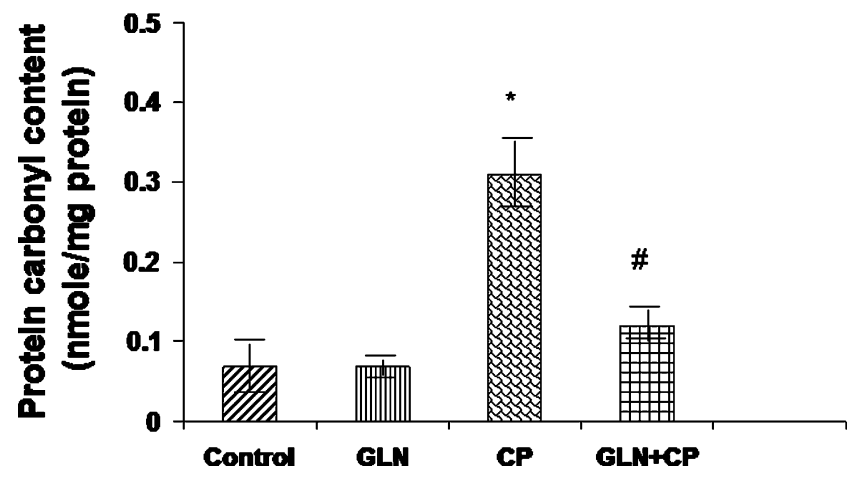

Fig. 3 Protein carbonyl content in the bladders of control rats and experimental rats. Data represent mean $\pm \mathrm{SD}$ of five to seven rats. ${ }^{*} P$ $<0.01$ vs control, GLN, ${ }^{\#} P<0.01$ vs CP 


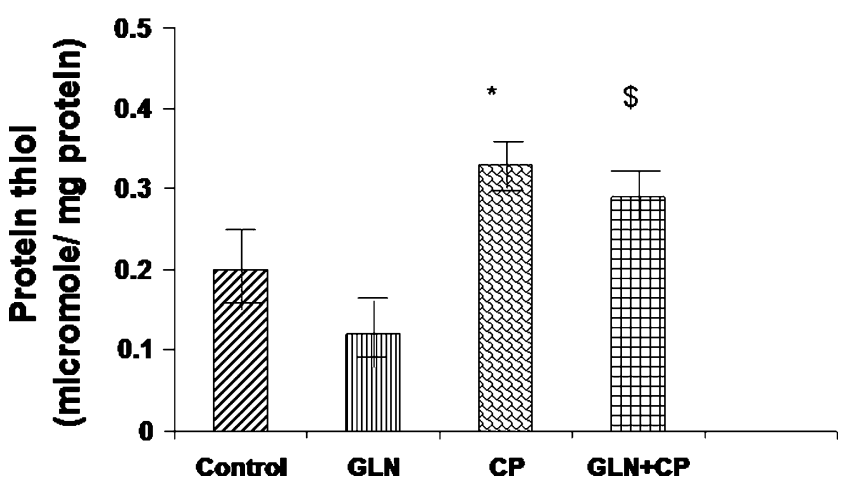

Fig. 4 Protein thiol in the bladders of control rats and experimental rats. Data represent mean \pm SD of $5-7$ rats. ${ }^{*} P<0.01$ vs control, ${ }^{\$} P<0.01$ vs GLN

\section{Myeloperoxidase Activity}

A threefold increase in myeloperoxidase (MPO) activity was observed in the bladders of CP-treated rats as compared with control $(P<0.01)$. Pretreatment with glutamine partially but significantly reduced CP-induced elevation in MPO activity $(P<0.05)$ (Fig. 5).

\section{Discussion}

In the present study, the treatment of rats with $\mathrm{CP}$ resulted in enhanced oxidative stress and neutrophil infiltration in the bladder as evidenced by enhanced MDA level, protein thiol level, protein carbonyl content, and MPO activity. Pretreatment with glutamine significantly attenuated CPinduced oxidative stress and neutrophil infiltration as evidenced by decrease in MPO activity, which is one of the markers of neutrophil infiltration [24]. However, surprisingly, glutamine did not prevent $\mathrm{CP}$-induced bladder damage.

Several antioxidants and oxidative stress inhibitors have been shown to protect against $\mathrm{CP}$-induced oxidative stress

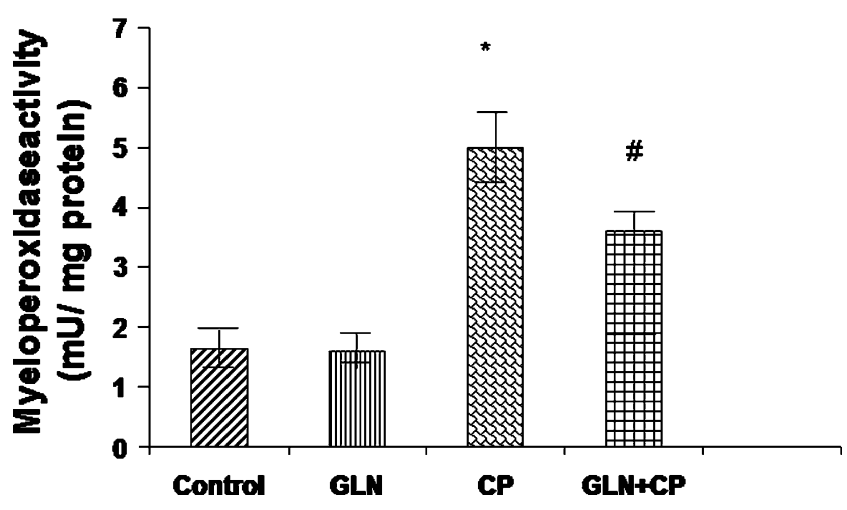

Fig. 5 MPO activity in the bladders of control rats and experimental rats. Data represent mean $\pm \mathrm{SD}$ of five to seven rats. $* P<0.01$ vs control, GLN, ${ }^{\#} P<0.05$ vs CP and hemorrhagic cystitis. These include $\alpha$-tocopherol, $\beta$-carotene, taurine, and melatonin [4-6]. In a recent study, we have shown that aminoguanidine pretreatment attenuates CP-induced oxidative stress, decrease in the activities of antioxidant enzymes, and reduced bladder damage [25].

Neutrophils are suggested to be one of the sources of reactive oxygen species that cause enhanced lipid peroxidation [26]. Recent studies demonstrate that glutamine prevents neutrophil recruitment and infiltration and attenuates liposaccharide-induced acute lung injury. This effect is suggested to be related to its antioxidant property [27-29]. Yeh et al. [28] have demonstrated that under septic conditions, GLN administration enhances lymphocyte function, attenuate interactions between polymorphonuclear lymphocytes and endothelium, and thus decreases neutrophil infiltration into tissues. In the present study, CP treatment resulted in increased MPO activity in the bladders of rats. GLN pretreatment prevented CP-induced neutrophil infiltration as reflected by the MPO activity, but did not prevent the cystitis.

Protein thiol level was elevated in the bladders of rat that were treated with CP. This is probably a defense mechanism in the bladder in response to increased oxidative stress [30].

Todora et al. [17] have recently demonstrated that GLN pretreatment ( $1 \mathrm{~g} / \mathrm{kg}$ body weight) attenuates CP-induced oxidative stress and protects against $\mathrm{CP}$-induced cardiotoxicity in rats. However, we could not demonstrate the protective effects of GLN on the bladder, although it attenuated CP-induced oxidative stress. We suggest that $\mathrm{CP}$-induced cardiotoxicity and urotoxicity may involve different mechanisms.

In the present study, although glutamine pretreatment significantly attenuated CP-induced oxidative stress and neutrophil infiltration, it was not effective in preventing CP-induced bladder damage. These observations suggest that oxidative stress may not be the only mechanism by which CP induces bladder damage. While antioxidants such as tocopherol, carotene, taurine, and melatonin protect against $\mathrm{CP}$-induced $\mathrm{HC}$, glutamine does not do so. The reason is not clear. It is noteworthy to mention here that the agents that were shown to be protective against $\mathrm{CP}$-induced OS and bladder damage, namely $\alpha$ tocopherol, $\beta$ carotene, melatonin, and aminoguanidine, are not only potent antioxidants/ROS scavengers but are also strong inhibitors of nitrosative stress. Nitrosative stress is overproduction of reactive nitrogen species (RNS) such as nitric oxide and peroxynitrite. There is a very close relationship between ROS and RNS. To be precise, superoxide anion is an important ROS that reacts with nitric oxide and forms peroxynitrite radical. Peroxynitrite is a strong oxidant and nitrating species that can cause destruction of host cellular constituents. Peroxynitrite can oxidize and covalently 
modify all types of biomolecules, such as membrane lipids, thiols, proteins, and DNA [31-33]. Therefore, the protective effect of alpha tocopherol, beta carotene, melatonin, and aminoguanidine on $\mathrm{CP}$-induced $\mathrm{HC}$ may be attributed to their inhibition of not only oxidative stress but also nitrosative stress. Thus far, glutamine has not been shown to have any effect on nitrosative stress to the best of our knowledge. This may explain why GLN does not protect against $\mathrm{CP}$-induced hemorrhagic cystitis although it attenuated $\mathrm{CP}$-induced oxidative stress significantly while the other antioxidants had a protective effect.

In summary, the present study shows that glutamine attenuates $\mathrm{CP}$-induced oxidative stress but does prevent $\mathrm{CP}$-induced bladder damage. This suggests that mechanisms other than oxidative stress such as nitrosative stress may also be involved. We suggest that it is necessary to clarify the utility of glutamine as a uroprotective agent.

Acknowledgement The study was supported by the Department of Science and Technology (DST), New Delhi, India.

\section{References}

1. ]Dollery C (1999) Cyclophosphamide. In: Dollery C (ed) Therapeutic drugs. Churchill Livingstone, Edinburg, pp 349353

2. Wong TM, Yeo W, Chan LW, Mok TS (2000) Hemorrhagic pyelitis, ureteritis, and cystitis secondary to cyclophosphamide: case report and review of literature. Gynecol Oncol 76:223-225

3. Walker RD, Sommerkamp H (1998) Hemorrhagic cystitis after high dose chemotherapy. An interdisciplinary problem. Urologie A 37:516-521

4. Sadir S, Deveci S, Korkmaz A (2007) Alpha tocopherol, beta carotene, and melatonin administration protects cyclophosphamide induced oxidative damage to bladder tissue in rats. Cell Biochem Funct 25:521-552

5. Topal P, Oztas Y, Korkmaz A (2005) Melatonin ameliorates bladder damage induced by cyclophosphamide in rats. J Pineal Res 38:272-277

6. Abd-Allah AR, Gado AM, Al-Majed AA et al (2005) Protective effect of taurine against cyclophosphamide-induced urinary bladder toxicity in rats. Clin Exp Pharmacol Physiol 32:167-172

7. Roth E (2008) Nonnutritive effects of glutamine. J Nutr 138:2025S-2031S

8. Matés JM, Pérez-Gómez C, Núñez de Castro I, Asenjo M, Márquez J (2002) Glutamine and its relationship with intracellular redox status, oxidative stress and cell proliferation/death. Int $\mathrm{J}$ Biochem Cell Biol 34:439-458

9. Häussinger D, Roth E, Lang F, Gerok W (1993) Cellular hydration state: an important determinant of protein catabolism in health and disease. Lancet 341:1330-1332

10. Hong RW, Rounds JD, Helton WS, Robinson MK, Wilmore DK (1992) Glutamine preserves liver glutathione after lethal hepatic injury. Ann Surg 215:114-119

11. Amores-Sánchez MI, Medina MA (1999) Glutamine, as a precursor of glutathione, and oxidative stress. Mol Genet Metab 67(2):100-105

12. Heyland DK, Dhaliwal R, Day AG, Muscedere J, Drover J, Suchner U, Cook D (2006) Reducing Deaths due to OXidative
Stress (The REDOXS Study): rationale and study design for a randomized trial of glutamine and antioxidant supplementation in critically-ill patients. Proc Nutr Soc 65:250-263

13. Kul M, Vurucu S, Demirkaya E, Tunc T, Aydinoz S, Meral C, Kesik V, Alpay F (2009) Enteral glutamine and/or arginine supplementation have favorable effects on oxidative stress parameters in neonatal rat intestine. J Pediatr Gastroenterol Nutr 49:85-89

14. Peterson DE, Jones JB, Petit RG II (2007) Randomized, placebo controlled trial of saforis for prevention and treatment of oral mucositis in breast cancer patients receiving anthracycline-based chemotherapy. Cancer 109:322-331

15. Choi K, Lee SS, Oh SJ, Lim SY, Jeon WK, Oh TY, Kim JW (2007) The effect of oral glutamine on 5-fluorouracil/leucovorininduced mucositis/stomatitis assessed by intestinal permeability test. Clin Nutr 26:57-62

16. Wang WS, Lin JK, Chen WS, Jiang JK, Wang HS, Chiou TJ, Liu JH, Yen CC, Chen PM (2007) Oral glutamine is effective for preventing oxaliplatin-induced neuropathy in colorectal cancer patients. Oncologist 12:312-319

17. Todorova V, Vanderpool D, Blossom S, Nwokedi E, Hennings L, Mrak R, Klimberg VS (2009) Oral glutamine protects against cyclophosphamide-induced cardiotoxicity in experimental rats through increase of cardiac glutathione. Nutrition 25:812-817

18. Ahluwalia A, Maggi CA, Santicioli P, Lecci A, Giuliani S (1994) Characterization of the capsaicin-sensitive component of cyclophosphamide induced inflammation in the rat urinary bladder. $\mathrm{Br} \mathrm{J}$ Pharmacol 111:1017-1022

19. Ohkawa H, Ohishi N, Yagi K (1979) Assay for lipid peroxides in animal tissues by thiobarbituric acid reaction. Anal Biochem 95:351-358

20. Sohal RS, Agarwal S, Dubey A, Orr WC (1993) Protein oxidative damage is associated with life expectancy of houseflies. Proc Natl Acad Sci USA 90:7255-7259

21. Sedlak J, Lindsay RH (1968) Estimation of total, protein-bound, and nonproteinsulfhydryl groups in tissue with Ellman's reagent. Anal Biochem 25:192-205

22. Doan T, Massarotti E (2005) Rheumatoid arthritis, an overview of new and emerging therapies. J Clin Pharmacol 45:751-762

23. Lowry OH, Rosebrough NJ, Farr AL, Randall RJ (1951) Protein measurement with the folin phenol reagent. J Biol Chem 93:265275

24. Perkins GD, Nathani N, McAuley DF, Gao F, Thickett DR (2007) In vitro and in vivo effects of salbutamol on neutrophil function in acute lung injury. Thorax 62:36-42

25. Abraham P, Rabi S, Selvakumar D (2009) Protective effect of aminoguanidine against oxidative stress and bladder injury in cyclophosphamide-induced hemorrhagic cystitis in rat. Cell Biochem Funct 27:56-62

26. Al Laham F, Kälsch AI, Heinrich L, Birck R, Kallenberg CG, Heeringa P, Yard B (2010) Inhibition of neutrophil-mediated production of reactive oxygen species (ROS) by endothelial cells is not impaired in anti-neutrophil cytoplasmic autoantibodies (ANCA)-associated vasculitis patients. Clin Exp Immunol (in press)

27. Ohno Y, Ormstad K (1985) Formation, toxicity and inactivation of acrolein during biotransformation of cyclophosphamide as studied in freshly isolated cells from rat liver and kidney. Arch Toxicol 57:99-103

28. Yeh CL, Hsu CS, Yeh SL, Lin MT, Chen WJ (2006) Dietary glutamine supplementation reduces cellular adhesion molecule expression and tissue myeloperoxidase activity in mice with gutderived sepsis. Nutrition 22:408-413

29. Zhang F, Wang X, Wang W, Li N, Li J (2008) Glutamine reduces TNF-alpha by enhancing glutathione synthesis in lipopolysaccharidestimulated alveolar epithelial cells of rats. Inflammation 31:344-350 
30. Kon T, Tanigawa T, Hayamizu K, Shen M, Tsuji T, Naito Y, Yoshikawa T (2004) Singlet oxygen quenching activity of human serum. Redox Rep 9(6):325-330

31. Radi R, Beckman JS, Bush KM (1991) Peroxynitriteinducedmembrane lipid peroxidation: the cytotoxic potential of superoxide and nitric oxide. Arch Biochem Biophys 288:481
32. Szabo C, Zingarelli B, O’Connor M (1996) DNA strandbreakage, activation of poly (ADP-ribose) synthase and cellularenergy depletion are involved in the cytotoxicity of macrophages, and smooth muscle cell exposed to peroxynitrite. Proc Natl Acad Sci 93:1753-1758

33. Radi R (2004) Nitric oxide, oxidants, and protein tyrosine nitration. Proc Nat Acad Sci USA 101:4003-4008 